\title{
Development of a microcomputer system for verbal interaction analysis
}

\author{
DAVID S. HARGROVE and THOMAS A. MARTIN \\ University of Nebraska, Lincoln, Nebraska 68588
}

\begin{abstract}
Verbal interaction analysis has been demonstrated to be a valuable procedure for research on temporal, noncontent variables in dyadic interviews. Temporal variables include durations of utterance, reaction time latency, initiative time latency, and overlap, which are recorded for both parties in the interview. Instruments for the measurement of these variables have been both complex and expensive. An Apple II microcomputer is programmed to record the four temporal variables in verbal interaction analysis, providing a portable, less expensive, and convenient instrument.
\end{abstract}

Investigation of the dyadic interview has been an important component of research in psychotherapy process (Craig, 1966; Kiesler, Mathieu, \& Klein, 1967; Matarazzo, Wiens, Matarazzo, \& Saslow, 1968; Truax, 1970), verbal conditioning (Heller \& Marlatt, 1969; Kanfer, 1968), and personality (Mehrabian, 1972; Wiens, Harper, \& Matarazzo, 1980). These studies typically have been concerned with a single verbal behavior or a combination of verbal behaviors to make individual assessments of individuals or analytical statements about processes of interaction.

A significant portion of a person's interview behavior is speech behavior. Matarazzo and Wiens (1972) point out that there have been two relatively separate approaches to studying speech behavior. The first is content analysis, focusing on what the speaker is saying, and including studies of the use of grammatical units, themes, or emotionally loaded words. A second approach to studying speech is to focus on how speech is stated. This includes acoustical qualities and temporal qualities of interactive speech, characterized as studies of the noncontent dimensions of speech.

One particularly useful approach to the analysis of temporal variables of interviews is verbal interaction analysis (Matarazzo \& Wiens, 1972). This procedure focuses on four temporal, noncontent speech behaviors that have been shown to be important elements of psychotherapeutic as well as other interview contexts.

Several instruments have been developed to efficiently measure these temporal speech variables. They range from a crude manually operated Astroline hydrothermal chart recorder (Hargrove, 1974) to the multipleinteraction recorder (Matarazzo \& Wiens, 1972; Morris, Johnston, Bailey, \& Wiens, 1968), a relatively expensive but efficient instrument for measuring interview interaction.

This paper identifies and defines the temporal qualities of speech behavior that are important in one facet of interview research, briefly describes some of the instruments that have been devised to measure these qualities, and describes both the hardware and software of a recently developed microcomputer program for verbal interaction analysis.

\section{UNITS OF VERBAL INTERACTION ANALYSIS}

The most comprehensive and systematic definitions of the basic units of temporal speech behaviors have been developed by Matarazzo and Wiens (1972). The four speech behaviors that are the focus of verbal interaction analysis are duration of utterance, reaction time latency, initiative time latency, and interruption.

\section{Duration of Utterance}

The first unit of speech measured in verbal interaction analysis is the duration of utterance. It is defined by Matarazzo and Wiens (1972) as "the total duration of time it takes for a speaker to emit all the words he is contributing in that particular unit of exchange (as this would be judged by common social standards)" (p.6). Durations of utterance usually are reported as frequencies and mean lengths for analysis. Mean length of a duration in an interview is calculated by summing the single durations emitted and dividing by the number of occurrences. This is determined for both speakers.

\section{Reaction Time Latency}

The second unit of analysis is reaction time latency, or the duration of silence that separates one speaker's completed utterance from the other speaker's beginning of utterance. Typically, reaction time latency is reported as a frequency and a mean, which is calculated by summing the total reaction time throughout the conversation and dividing by the number of occurrences.

\section{Initiative Time Latency}

The third unit of analysis is initiative time latency. This is a period of silence or pause in a duration of utter- 
ance in which the second person does not respond and the original speaker continues. Another way of describing this unit is a cessation of talking by a speaker, clearly signifying a pause within an utterance, to which the other speaker does not respond, after which the original speaker resumes the utterance. Mean length of initiative time latency, calculated by summing all the initiative time durations and dividing by the number of occurrences, and the frequency generally are reported. The percentage of initiative time latency may be calculated by dividing the frequency of initiative latency units by the frequency of durations of utterance.

\section{Overlap}

The fourth unit is interruption or overlap. This is defined as simultaneous speech by the two persons in the dyad. The interruption is attributed to the person who speaks while the other person's duration is in progress. It typically is reported as frequency (the total number of occurrences of simultaneous speech) and percentage (the frequency of interruptions attributed to a person divided by the total number of durations of that person).

Individual data typically are reported for both persons in the interview setting. The collection of data is dependent on an observer/recorder who has a precise understanding of the variables to be measured. All data in verbal interaction analysis are contributed by the observer/recorder. Typically, reliability data for observer/ recorders are reported and are quite high. In some cases, observer/recorders record data from audio-tape recordings of interviews, and in others, data are recorded directly while live interview sessions occur.

\section{INSTRUMENTS FOR VERBAL INTERACTION ANALYSIS}

\section{Interaction Chronograph}

The first mechanical instrument reported for measuring temporal, noncontent speech behaviors was the Chapple interaction chronograph. Prior to developing the chronograph, Chapple used a stopwatch and ruled paper for tabulating data during the interview interaction. He then developed a device with a mechanical drive that rolled paper at a constant rate of speed. Individual ink pens were depressed to record the times of verbal activity for both persons in the interview setting. The computations required to make the data useful were quite tedious. Chapple then designed the interaction chronograph, which electrically recorded the temporal variables and computed measurements originally performed by hand (Chapple \& Arensberg, 1940).

Matarazzo and Wiens (1972) used the interaction chronograph during the early years of verbal interaction research. The need for a more rapid means of processing data led to the development of the interaction recorder (Johnston, Jansen, Weitman, Hess, Matarazzo, \& Saslow, 1961), which consisted of a Computer Measurements Corporation timer and a Tally Model 420 tape perfora- tor. The punched tape was read by a Burroughs E101 or an IBM 1100 -series computer. Computer output provided a printed chronological analysis of the verbal interaction variables.

\section{Multiple-Interaction Recorder}

Morris et al. (1968) reported the development of the multiple-interaction recorder. This instrument improved the interaction recorder by expanding the number of buttons from 2 to 20 , allowing the recording of many more persons or behaviors, and it utilized a computerscorable magnetic tape instead of the tape perforator.

Matarazzo and Wiens (1972) point out the large initial development cost and annual operating costs of these instruments, as well as other similar instruments reported (Cassotta, Feldstein, \& Jaffe, 1964; Hargreaves \& Starkweather, 1959). Matarazzo, Holman, and Wiens (1967) reported a simple means of measuring the same temporal variables using only a stopwatch and tape recorder. Computations and analyses of data, however, are grueling and tedious.

The system described is designed to meet the demands of recording, computing, and analyzing verbal interaction data and to remain within realistic financial limits. Additionally, it offers a high degree of mobility to enable researchers to work in a variety of settings.

\section{MICROCOMPUTER SYSTEM}

The Apple Il microcomputer was selected for this application due to its relatively low price and availability to the researchers. The system on which the software was developed is composed of an Apple II microcomputer with an Apple language card, an Apple clock (Mountain Hardware), two Apple Disk II drives, a Sanyo monitor, and an NEC Spinwriter 5510 with a BDT ASF 160 automatic sheet feeder. A four-button interface box utilizing the Apple II game connector (Spaulding, Hargrove, Crinean, \& Martin, 1981) is also part of the system. However, the software described below does not require the use of the interface box; the buttons on game paddles would suffice.

\section{SOFTWARE}

The software is written in UCSD PASCAL. It utilizes a library described elsewhere (Spaulding, et al., 1981) that contains machine language software to access the clock.

\section{Constants}

Two constants are declared in the program, one of which determines the number of milliseconds that elapse between samples. The second constant determines the number of samples to be collected. Constants are used to allow ease in changing the frequency and number of samples without extensive modification of the program. 


\section{Execution of Program}

Upon executing the program, the operator is prompted to enter a character indicating whether data are to be retrieved for analysis from an existing file or whether new data are to be generated. The name of the data file to be accessed or created is also entered. If new data are to be generated, the operator codes the verbal interaction data from audio tape by pressing one button on the interface box when the therapist is talking and another when the client is talking. During periods of silence, no buttons are pressed. Overlaps in speech require that the operator press both buttons at once. In the current version of the program, the buttons are then read by the microcomputer every $200 \mathrm{msec}$. Visual feedback is provided to the operator on the CRT; "therapist" or "client" appears if one button is depressed, "none" if no buttons are depressed, and "both" if both buttons are depressed. The collection of data can be prematurely terminated by hitting any key on the keyboard of the computer.

\section{Timing}

Timing is achieved in the program by accessing the clock and waiting until a multiple of 200 msec is reached and then executing the procedure that reads the buttons. Obviously, if one attempts to collect samples at a rate faster than the time required for reading the buttons, storing the results, and providing visual feedback, errors in timing will occur. The lower limit on the intersample interval given the present form of the program appears to be $200 \mathrm{msec}$. This is more than adequate for the application at hand.

\section{Data Storage}

The raw data are represented as two Boolean arrays, that is, arrays of true or false values. There is one array for each of the persons in the interaction. Values of "true" indicate that the person was speaking at that point in time; values of "false" indicate that he or she was not speaking. At the termination of the sampling procedure, the raw data are stored on disk. The purpose of storing the data in this form, rather than following its analysis, is to allow for the possibility of reanalysis in the future. The retention of raw data preserves flexibility for the researcher and provides the opportunity for efficient rather than cumbersome reanalysis of the data.

\section{Types of Interaction}

Interactions between therapist and client generally involve periods of silence, as well as verbalizations by the client and therapist. Reaction time latency and initiative time latency can be defined by a sequence of three interactions. For example, reaction time latency on the part of the therapist requires that the client speak, followed by silence and then by speech by the therapist. Sequences of interaction for each variable are presented in Table 1. Duration and overlap do not require a three-interaction sequence, but they can be defined within such a format. The interval of interest in each of these sequences is the length of the second interaction in the sequence.

\section{Data Analysis}

All possible combinations of three interactions can be represented in a three-dimensional matrix with four positions on each axis, one for each type of interaction. The analysis of the verbal interactions performed by the software involves transforming the Boolean data into such a three-dimensional matrix of records. Each record within the matrix contains the frequency with which that sequence of interaction occurred and the total number of seconds that elapsed during the second interaction of the sequence. The matrix is then accessed by procedures that provide the operator with hard copies of the data desired for each verbal interaction variable. Figure 1 is a sample printout.

\section{SUMMARY}

Verbal interaction analysis has been demonstrated to be a productive method of analysis of the temporal, noncontent variables of interviews. A number of machines have been designed to facilitate the measure-

Table 1

Temporal Sequences of Speech Representing Verbal Interaction Variables

\begin{tabular}{|c|c|c|c|c|}
\hline \multirow[b]{2}{*}{ Person } & \multirow[b]{2}{*}{ Variable } & \multicolumn{3}{|c|}{ Sequence of Speech } \\
\hline & & First & Second & Third \\
\hline Therapist & $\begin{array}{l}\text { Duration } \\
\text { Reaction Time Latency } \\
\text { Initiative Time Latency } \\
\text { Overlap }\end{array}$ & $\begin{array}{l}\text { any } \\
\text { client } \\
\text { therapist } \\
\text { client }\end{array}$ & $\begin{array}{l}\text { therapist } \\
\text { silence } \\
\text { silence } \\
\text { both }\end{array}$ & $\begin{array}{l}\text { any } \\
\text { therapist } \\
\text { therapist } \\
\text { any }\end{array}$ \\
\hline Client & $\begin{array}{l}\text { Duration } \\
\text { Reaction Time Latency } \\
\text { Initiative Time Latency } \\
\text { Overlap }\end{array}$ & $\begin{array}{l}\text { any } \\
\text { therapist } \\
\text { client } \\
\text { therapist }\end{array}$ & $\begin{array}{l}\text { client } \\
\text { silence } \\
\text { silence } \\
\text { both }\end{array}$ & $\begin{array}{l}\text { any } \\
\text { client } \\
\text { client } \\
\text { any }\end{array}$ \\
\hline
\end{tabular}


THERAPIST VARIABLES:
DURATION:

RT LATENCY :

$$
\begin{array}{rc}
\text { frequency: } & 25 \\
\text { mean duration: } & 2.81 \\
\text { talk/silence: } & 0.14
\end{array}
$$

$\begin{array}{crc}\text { RT LATENCY: } & \text { frequency: } & 20 \\ & \text { mean duration: } & 1.16 \\ \text { IT LATENCY: } & \text { frequency: } & 4 \\ & \text { mean duration: } & 2.90 \\ \text { OVERLAP: } & \text { frequency: } & 0 \\ \text { CLIENT VARIABLES: } & & \\ \text { DURATION: } & \text { frequency: } & 48 \\ & \text { mean duration: } & 8.38 \\ \text { talk/silence: } & 2.19 \\ \text { RT LATENCY: } & \text { frequency: } & 20 \\ & \text { mean duration: } & 1.08 \\ \text { IT LATENCY: } & \text { frequency: } & 27 \\ & \text { mean duration: } & 2.10 \\ \text { OVERLAP: } & \text { frequency: } & 0\end{array}$

Figure 1. Sample printout. Unit of mean duration is seconds. Talk/silence is the ratio of talking to silence.

ment and computation of verbal interaction data. They range from simple stopwatch and tape recorders to highly sophisticated, expensive computerized instruments that record, compute, and analyze data

The program described in this paper is a low-cost, portable microcomputer system developed to record, compute, and analyze relevant verbal interaction analysis data, providing immediate printed output. The procedure is useful for research in a variety of types of interviews, psychotherapy process research, and psychotherapy supervision.

Further refinement of this process could include the utilization of voice keys to replace the observer/recorder to precisely record a greater amount of data.

\section{REFERENCES}

Cassotta, L., Feldstein, S., \& Jaffe, J. AVta: A device for automatic vocal transaction analysis. Journal of the Experimental Analysis of Behavior, 1964, 7, 99-104.
Chapple, E. D., \& Arensberg, C. M. Measuring human relations: An introduction to the study of the interaction of individuals. Genetic Psychology Monographs, 1940, 22, 3-147.

Craig, K. D. Incongruencies between content and temporal measures of patients' responses to confrontation with personality descriptions. Journal of Consulting Psychology, 1966, 30, 550-554.

Hargreaves, W. A., \& Starkweather, J. A. Collection of temporal data with the duration tabulator. Journal of Experimental A nalysis of Behavior, 1959, 2, 179-183.

HaRgrove, D. S. Verbal interaction analysis of empathic and nonempathic responses of therapists. Journal of Consulting and Clinical Psychology, 1974, 42, 305.

Heller, K., \& Marlatt, G. A. Verbal conditioning, behavior therapy and behavior change: Some problems in extrapolation. In C. M. Franks (Ed.), Behavior therapy: Appraisal and status. New York: McGraw-Hill, 1969.

Johnston, G., Jansen, J., Weitman, M., Hess, H. F., Matarazzo, J. D., \& Saslow, G. A punched tape data preparation system for use in psychiatric interviews. Digest of the 1961 International Conference on Medical Electronics, July 1961, p. 17.

KanFER, F. H. Verbal conditioning: A review of its current status. In T. R. Dixon \& D. L. Horton (Eds.), Verbal behavior and general behavior theory. Englewood Cliffs, N.J: Prentice-Hall, 1968.

Kiesler, D. J., Mathiev, P. L., \& Klein, M. H. Patient experiencing level and interaction chronograph variables in therapy interview segments. Journal of Consulting Psychology, $1967,31,224$.

Matarazzo, J. D., Holman, D. C., \& Wiens, A. N. A simple measure of interviewer and interviewee speech durations. Journal of Psychology, 1967, 66, 7-14.

Matarazzo, J. D., \& Wiens, A. N. The interview: Research on its anatomy and structure. New York: Aldine-Atherton, 1972.

Matarazzo, J. D., Wiens, A. N., Matarazzo, R. G., \& Saslow, G. Speech and silence behavior in clinical psychotherapy and its laboratory correlates. In J. Shlien, H. Hunt, J. D. Matarazzo, \& C. Savage (Ed.), Research in psychotherapy (Vol. 3). Washington, D.C: American Psychological Association, 1968.

Mehrabian, A. Nonverbal communication. Chicago: AldineAtherton, 1972.

Morris, R. L., Johnston, G. I., Bailey, D. D., \& Wiens, A. N. A twenty-four channel temporal-event digital recording system. Medical Research Engineering, 1968, 7, 406-411.

Spaulding, W., Hargrove, D. S., Crinean, W. J., \& Martin, T. A microcomputer-based laboratory for psychopathology research in rural settings. Behavior Research Methods \& Instrumentation, 1981, 13, 616-623.

Truax, C. B. Length of therapist response, accurate empathy and patient improvement. Journal of Clinical Psychology, 1970, 26, 539-541.

Wiens, A. N., Harper, R. G., \& Matarazzo, J. D. Personality correlates of nonverbal interview behavior. Journal of Clinical Psychology, 1980, 36, 205-215. 